\title{
Advancing Supersonic Retropropulsion Using Mars-Relevant Flight Data: An Overview
}

\author{
Robert D. Braun* \\ University of Colorado at Boulder, Boulder, CO, 80309 \\ Brandon Sforzo ${ }^{\dagger}$ \\ Georgia Institute of Technology, Atlanta, GA 30332 \\ Charles H. Campbell ${ }^{\ddagger}$ \\ Lyndon B. Johnson Space Center, Houston, TX 77058
}

\begin{abstract}
Advanced robotic and human missions to Mars require landed masses well in excess of current capabilities. One approach to safely land these large payloads on the Martian surface is to extend the propulsive capability currently required during subsonic descent to supersonic initiation velocities. However, until recently, no rocket engine had ever been fired into an opposing supersonic freestream. In September 2013, SpaceX performed the first supersonic retropropulsion (SRP) maneuver to decelerate the entry of the first stage of their Falcon 9 rocket. Since that flight, SpaceX has continued to perform SRP for the reentry of their vehicle first stage, having completed multiple SRP events in Mars-relevant conditions in July 2017. In FY 2014, NASA and SpaceX formed a three-year public-private partnership centered upon SRP data analysis. These activities focused on flight reconstruction, CFD analysis, a visual and infrared imagery campaign, and Mars EDL design analysis. This paper provides an overview of these activities undertaken to advance the technology readiness of Mars SRP.
\end{abstract}

\section{Introduction}

Advanced robotic and human missions to Mars require landed masses well in excess of current capabilities. ${ }^{1}$ One approach to safely land these large payloads on the Mars surface is to extend the propulsive capability currently required during subsonic descent to supersonic initiation velocities (i.e. supersonic retropropulsion (SRP)). ${ }^{1,2}$ Significant work remains to characterize these flows and to design systems capable of human class missions to Mars.

SRP was identified as a challenge in NASA's Space Technology Entry, Descent and Landing Roadmap and was cited as being of high priority in the National Research Council Life and Physical Sciences Survey, Recapturing a Future for Space Exploration: Life and Physical Sciences Research for a New Era. In addition, SRP was identified as a critical path technology and baselined in a large number of NASA Mars EDL-SA concepts. ${ }^{3,4}$

\footnotetext{
* Dean of the College of Engineering and Applied Science, AIAA Fellow, bobby.braun@colorado.edu

${ }^{\dagger}$ Postdoctoral Fellow, Daniel Guggenheim School of Aerospace Engineering, AIAA Senior member, brandon.sforzo@gatech.edu

‡ Aerospace Engineer, NASA JSC Flight Projects \& Integration Office, AIAA Associate Fellow, charles.h.campbell@nasa.gov
} 
Initially studied in the $1960{ }^{\prime} \mathrm{s}^{5-7}$, interest in SRP technology has been recently renewed ${ }^{8,9}$ as the entry, descent and landing community considers approaches for landing more massive payloads on the surface of Mars. SRP technology efforts in the past decade have been aeroscience dominated and focused on understanding aerodynamic-propulsive flowfield interactions during supersonic conditions. ${ }^{10-14}$ Systems analysis, computational fluid dynamics simulations, and small-scale wind-tunnel testing ${ }^{15-16}$ have not identified any propulsive-aerodynamic interaction showstoppers for this technology. Blunt body aeroshell configurations have been the focus of this work. Flight dynamics simulations have demonstrated that SRP initiation generally occurs at a minimum altitude boundary subject to subsequent timeline constraints with resulting high values of thrust coefficient. SRP can also be utilized as additional control authority for precision landing. ${ }^{17}$ Computational fluid dynamics tools have been shown capable of capturing major flowfield features, including unsteadiness, albeit at considerable computational expense. ${ }^{13-14}$ Recent computational and experimental efforts have demonstrated that, in Mars relevant conditions, thrust requirements are sufficiently high to render the aerodynamic axial force contribution negligible. ${ }^{10-14}$ For these cases, there is little uncertainty on the total deceleration afforded by SRP. On the other hand, for thrust coefficients significantly below that required for steady-state deceleration in flight relevant conditions, uncertainty remains and flow stability issues are observed. This is also true of flight at higher angles of attack and for more slender vehicles. Generally, SRP aeroscience uncertainty is highest for the conditions least likely to be observed in flight (low-thrust coefficients and extremely high angles of attack) and aeroscience modeling fidelity is highest for flight-relevant conditions.

\section{SRP Flight Risks}

In August 2012, the entry, descent and landing community met at the Georgia Institute of Technology to discuss the risk associated with supersonic retropropulsion technology. At the time of this meeting, no rocket engine had ever been fired into an opposing supersonic freestream and flight test data was desired to improve technology readiness. A number of SRP technical issues were identified as having the potential to present risk to a future flight mission. These concerns included vehicle configuration, aeroscience, stability, aerothermodynamic, propulsion and potential mission infusion risks.

Vehicle Configuration: SRP flight system design is anticipated to be impacted by the human Mars exploration EDL configuration. Mature flight system designs would significantly increase understanding of the SRP system. Establishing valid designs is presently hampered by lack of definition of the human Mars exploration EDL configuration. At the most basic level, descent mass requirements are needed to size the propulsion system. SRP design is also intrinsically linked to vehicle packaging considerations, transitions between vehicle configurations during EDL, and aeroshell shape selection. Significantly more depth is needed in the design of one or more Mars descent vehicles to assess SRP flight risks. The vehicle/engine configuration selected is likely to have an effect on the combined propulsive/aerodynamic interactions. Vehicle configuration efforts should focus on minimizing the complexity and severity of potential SRP interactions as a means of reducing the development uncertainty and costs of these systems. 
Additional ground-based testing of flight relevant configurations with active engines is also warranted.

Aeroscience: The high thrust levels required of Mars SRP configurations dominate vehicle drag such that the impact of unsteady aerodynamics is negligible under steady-state operating conditions at low angles-of-attack. However, under some conditions (low thrust coefficients and/or extremely high angles-of-attack), the basic flow structure has the potential to lead to unsteady forces and torques on a thrusting spacecraft. Such forces and moments are challenging to model computationally and are subject to considerable uncertainty. Relevant during a very brief and transient event (engine start-up), these effects are likely small in magnitude relative to spacecraft inertia such that appreciable dynamics are not induced.

Stability: A majority of the computational and experimental work completed to date has focused on drag force prediction. A SRP system will be required to control the disturbance forces and torques generated. Preliminary analysis indicates this risk appears to be addressable with a thorough margin strategy. Additional stability and control analysis efforts are warranted to verify this strategy.

Aerothermodynamics: Thrusting into supersonic flow may present aerothermal challenges not encountered during subsonic propulsive deceleration. Convective and radiative heating from stagnation of the jet flowfield, complex shock interaction that potentially results in focused shear layer impingement, and aerothermal augmentation from heated jet exhaust products enveloping the vehicle are potential risks, as seen in Figure 1. Additionally, chemical contamination from exhaust products is a risk. While uncertain today, these aerothermal and contamination risks are likely addressable through proper engineering design and testing.

Propulsion: Engine bell stiffness and structural dynamics, induced by interactions with the flow before engine start, followed by reverse pressure after start are areas needing further characterization. Severe variation in the pressure environment may drive structural dynamics. If an SRP engine configuration includes embedded engines, heat rejection could also be a challenge. For SRP configurations utilizing the same engines for both high thrust maneuvers and soft landing, deep throttling and thrust vector control may be required beyond the current stateof-the art to provide a low velocity landing and prevent site alteration at landing. Finally, a dormant turbo machine during the many months of interplanetary cruise to Mars may pose a risk for pump-fed SRP propulsion systems. Detailed propulsion system design and ground-based testing is required as part human exploration vehicle configuration efforts.

Mission Infusion Potential: Propulsion is the only Mars entry, descent and landing technology that is intrinsically scalable across a wide range of missions. While not explicitly required for today's robotic science missions, one can envision the potential use of supersonic retropropulsion on a next decade robotic Mars mission in an architecture that accommodates significant propellant mass or as a robotic precursor to eventual human Mars exploration. Architecture-level parametric assessments have demonstrated that SRP is likely required to enable safe landing of Mars landed payload masses above approximately $5 \mathrm{t}$. As a result of the large gap between current capability (payload mass of approximately $1 \mathrm{t}$ ) and that needed for 
Mars human exploration missions (payload mass above $20 \mathrm{t}$ ), a progression of analysis and flight testing is required to mature SRP into a viable capability ready for infusion into a human exploration mission.

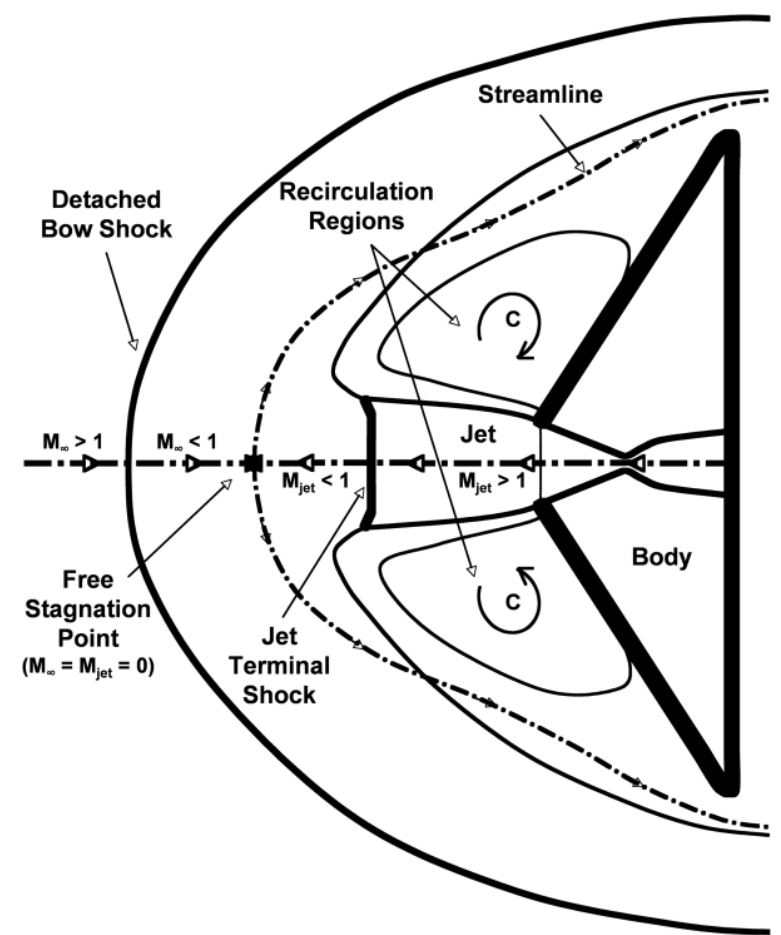

Figure 1 - Flowfield of jet issuing into an opposing supersonic freestream. (adapted in Ref 8 from Ref 6)

\section{NASA Propulsive Descent Technologies Project}

Based on the results of the Georgia Tech workshop, in FY 2013, a \$65M three-year NASA Space Technology Mission Directorate Game Changing Development project, focused on component level hot-fire testing, was proposed (FY14-FY16) to mitigate the risk of SRP adoption by future flight projects. This project included a progression of analysis, ground- based testing and sounding rocket testing to mature SRP into a capability ready for mission infusion. Experiments were designed for utilization of existing $100 \mathrm{lb}$ and $870 \mathrm{lb}$ spaceflight propulsion system. Under this plan, the project was to be initiated in Q4 of FY 2013.

Between October and December of 2013, an extensive literature review was completed of past SRP research. Gaps in existing research were identified for future development. The ability to successfully transition from a hypersonic entry vehicle configuration during EDL to SRP steadystate operation was considered a significant contributor to overall mission uncertainty. Separation events during atmospheric flight elevate overall system risk and uncertainty due to risks of recontact events with jettisoned mass and potential damage to the entry body. Previous Mars missions had performed subsonic separation and transition events similar to those required to utilize SRP. However, little work had been performed to characterize the aerodynamics and 
multibody dynamics of separation events during a supersonic transition. Results of this literature review include recommendations for future investigation into this area.

In this same timeframe, CFD research focused on validating steady state computational approaches to analyze SRP flowfield structures and their effects on vehicle aerodynamics and performance. In particular, the effect of vehicle configuration on SRP flow fields was examined. Investigations examined forebody nozzle configurations and aft-body nozzle configurations for a variety of flow regimes. To aid ongoing CFD efforts, an analytical modeling technique was developed for SRP-specific flow plume structures, providing insight to aid more computationally-expensive, higher-fidelity analyses. ${ }^{10}$ This technique was shown to effectively determine plume structure and resulting bow shock structure for single and three nozzle SRP configurations. Higher-fidelity computation methods were shown to agree favorably with these analytical approaches for zero angle of attack configurations in Mach 2 freestream flow.

\section{Reusable Rockets: A Game Changing Demonstration of SRP}

On September 29, 2013, SpaceX performed the first supersonic retropropulsion maneuver to decelerate the reentry of the first stage of their Falcon 9 rocket (Figure 2). At the time, SpaceX noted, "Though not a primary mission objective, SpaceX was also able to initiate two engine relights on the first stage. For the first restart burn, we lit three engines to do supersonic retro propulsion, which we believe may be the first attempt by any rocket stage. The first restart burn was completed well and enabled the stage to survive reentering the atmosphere in a controlled fashion.”

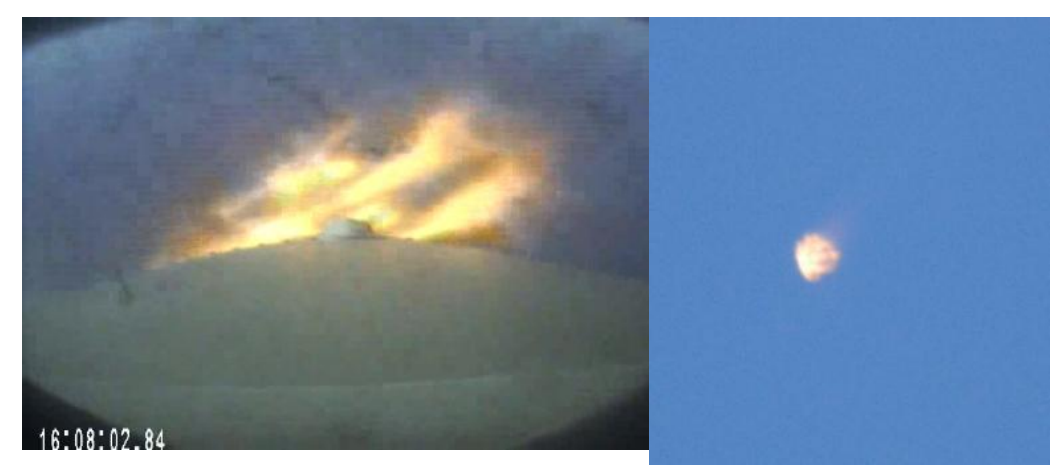

Figure 2 - Imagery of first SpaceX SRP event from onboard camera (L); ground imaging (R).

Space X has continued to perform SRP for the reentry of their vehicle first stage. As of July 2017, SpaceX has performed multiple SRP events in Mars relevant conditions.

As a result of this flight, in FY 2014, the NASA Propulsive Descent Technology (PDT) project was reformulated as a three-year public-private partnership between NASA and SpaceX. An integrated team of personnel from across NASA, industry, and academia collaborated in execution of this reformulated project. From the initial program that had been approved in FY13, the total project resources were reduced to below $\$ 10 \mathrm{M}$. Earlier plans for ground-based testing and sounding rocket flights were descoped, and the team's focus shifted to:

- Development and execution of a Non-Reimbursable Space Act Agreement (NRSAA) 
- Flight data analysis of SpaceX SRP events

- Data acquisition (visual and thermography) of a future SpaceX first-stage SRP event

- CFD analysis of a SpaceX first-stage SRP event

- Design analysis activities in support of SpaceX Mars efforts

- Design analysis of large scale Mars EDL systems utilizing SRP

The team was fully transitioned to this mode of operation by January 2014 and successfully concluded in December 2016. Results of this activity included flight reconstruction of multiple Mars-relevant SRP maneuvers ${ }^{18}$, remote airborne infrared and visual spectra imagery ${ }^{19}$, CFD analysis ${ }^{20}$, and Mars EDL design analysis. The following section provides an overview of these results. More detail of these activities is provided in Refs 18-20.

\section{Results and Discussion}

\section{Flight Reconstruction Analysis}

Vehicle telemetry data have been analyzed and compared for two SpaceX Falcon 9 first stage flights. Analysis focused on the supersonic retropropulsion segment of the descent, that SpaceX terms the entry burn. This phase of flight was confirmed in the telemetry by correlation to the engine chamber pressure. As shown in Figure 3, portions of the entry burn segment of certain flights fell within the range of Mach number and dynamic pressures that match and/or bound anticipated Mars SRP initiation conditions. Specifically, the F9-10 flight transited this Mars entry initiation regime, while F9-13 operated close to this regime and results remain relevant.

Onboard data for those flights were analyzed to assess and understand the range of attitudes and attitude rates, demonstrating vehicle controllability during engine startup and throughout SRP. No discrepancies were observed which were outside reasonable attitudes and rates for the vehicle. Furthermore, engine thrust vectoring commands and responses were also analyzed and compared against attitude rates during engine startup and SRP. These assessments highlighted that the Falcon 9 SRP implementation is robust.

Each of the entry vehicles were also outfitted with a combination of temperature and heat flux transducers to observe the effects of aerothermal heating. Through trajectory reconstruction, the relative orientation of the vehicle to the opposing flow was compared to the measured heating trends. Upon SRP initiation, heat fluxes rise as a result of the high enthalpy rocket plume interacting with the surface of the first stage vehicle. Vehicle base temperatures rise throughout SRP and fall immediately following engine shutdown. The locations of higher heating rates were well correlated with the stagnation point of the incoming flow, as determined by the trajectory reconstruction. This orientation to the flow was also confirmed by external pressure transducers, many of which were co-located with the temperature transducers.

Fourier transform analysis was also performed on high speed transducers to detect dynamic effects, particularly at SRP engine start up. Engine combustion chamber pressures showed negligible dynamic response upon engine startup, within the Nyquist spectral range available. Additionally, high speed strain gauge responses were recorded and showed low amplitude, low 
frequency, response during SRP that are typical. These vehicle dynamics were compared to plume shedding observed though airborne imagery with little correlation.

The nominal results observed from the detailed analysis of abundant vehicle sensor data supports applicability of SRP at Mars relevant conditions. No showstoppers were identified for this technology. Comparable trends from external pressure measurements between flights and heating values also supports the repeatability of these effects. The absence of dynamic response during SRP engine start is a promising experimental result for the stability of this maneuver.

Furthermore, vehicle attitude and control response indicate acceptable control margins during SRP.

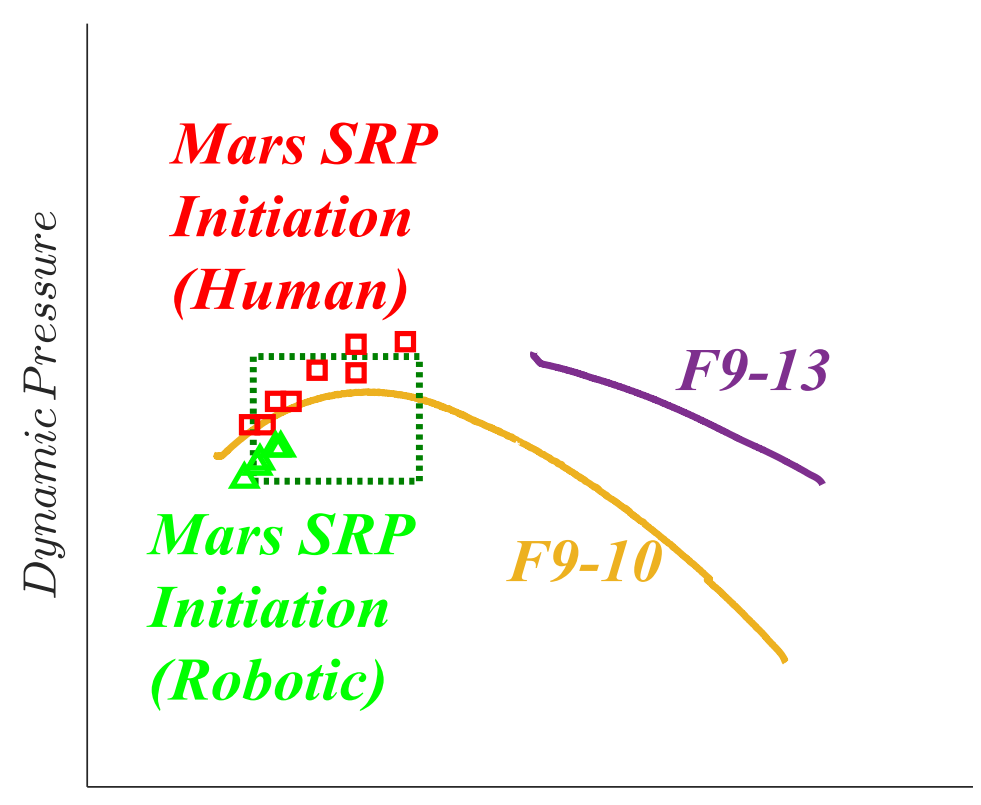

Mach Number

Figure 3 - Flight environment during the SRP entry burn phase for the two flights. The dashed box represents the range of conditions expected for Mars entry burn initiation.

\section{Airborne Imagery:}

Infrared observations were made of the SpaceX Falcon 9 flight F9-13 first stage booster during a recovery flight test on September 19,2014. Complementary thermal datasets were obtained by two aircraft equipped with long-range optical sensor systems: a US Navy NP-3D and a NASA high altitude WB-57. The planning, coordination and data analysis associated with an observation of a booster reentering along a suborbital trajectory posed unique challenges to the observation team. The remote imagery campaign was designed to provide insight into the flight environment and vehicle behavior associated with deceleration through supersonic retropropulsion. 
Thermal imaging equipment was calibrated prior to F9-13 observation to capture a thermal range consistent with expected vehicle temperatures. The optically dense plume that enveloped the vehicle during SRP prevented extraction of hardbody surface temperatures derived from the infrared measurements. Furthermore, the higher temperatures of this plume exceeded the calibrated thermal range, and therefore saturated imagery, obscuring thermal extraction during engine-on conditions.

While the environments associated with a launch vehicle in powered and unpowered flight required an extension of previous remote imagery techniques in order to extract engineering data, booster surface temperatures immediately before and after the SRP maneuver were consistent with the expected phenomenology. Surface temperatures from the independent observations were in good agreement with each other (and discrete thermocouple measurements obtained during a previous flight test) indicating the robustness of the processes used to improve the quality of the imagery while preserving radiometric accuracy. Temporal trends of surface temperature are reasonable and generally exhibited a constant value prior to SRP followed by modest temperature increase and a subsequent cooling trend after the SRP maneuver was terminated. Numerous lessons learned during the observation attempts culminating in the infrared observation were documented including those associated with data quality, the operations timeline, and range and aircraft operations.
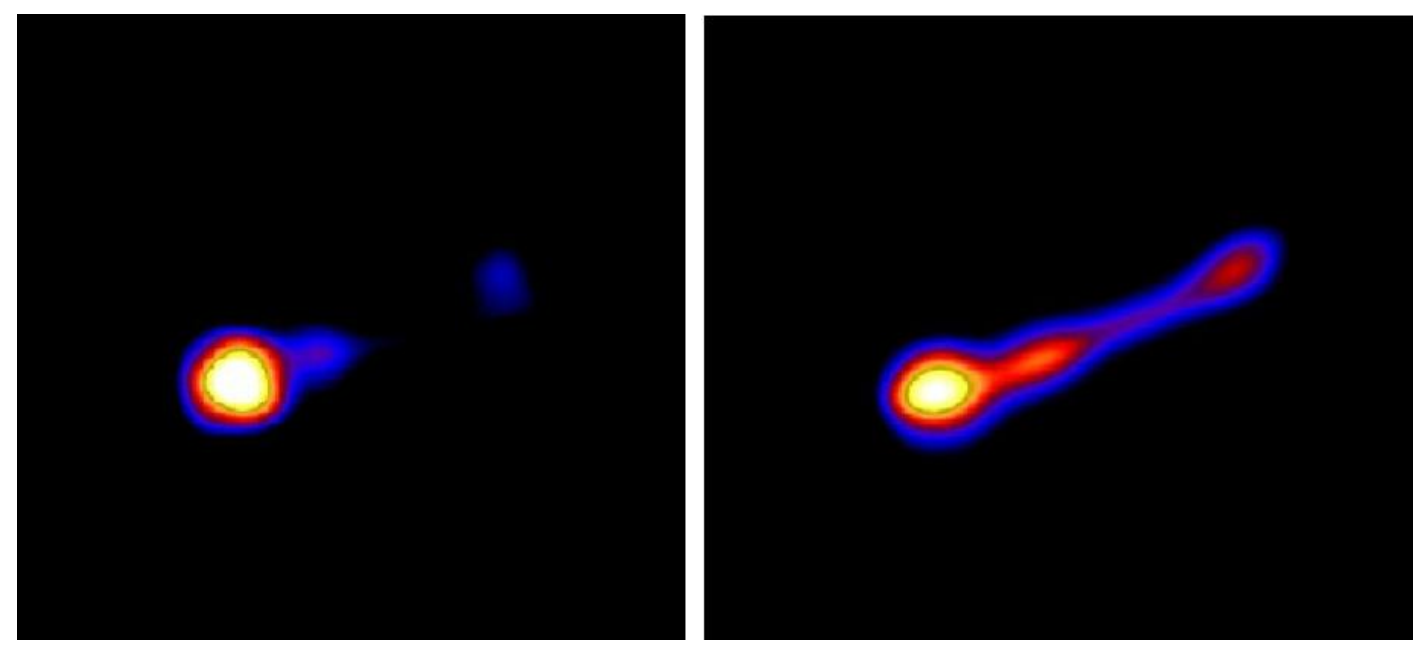

Figure 4 - Thermal imagery of vehicle just prior to and just following SRP phase, Ref 19.

\section{CFD Analysis:}

A critical aspect of NASA's SRP technology maturation efforts focused on calibrating and advancing computational methods to predict the complex flowfield and resulting aerodynamic heating, and aerodynamic-propulsive forces and moments. Despite differences in geometry and engine configuration compared to Mars EDL concepts, the SpaceX Falcon 9 flight data set provided a valuable opportunity to compare four NASA CFD codes against flight data in Mars relevant conditions. NASA personnel performed Reynolds-Averaged Navier-Stokes power-on simulations of SpaceX Falcon 9 first-stage entry before receiving the flight data. Comparisons 
were then made between each code and the flight data for flight F9-10, with a focus on base heating, base pressure, and total forces and moments. Though the CFD codes tended to overpredict the Falcon 9 engine thrust, NASA used the calibration exercise to establish best practices for Mars applications, to compare each code to flight data, and identify future ground-based testing needs to further reduce Mars supersonic retropropulsion technology risk. Specifically, challenges were overcome to handle the geometric and flowfield complexity, very large grid and memory requirements, high nozzle pressure ratios and thrust coefficients, which will be valuable lessons for Mars-relevant vehicles. The CFD comparisons show encouraging prediction capabilities for both supersonic retropropulsion-induced base heating and aerodynamic forces and moments.

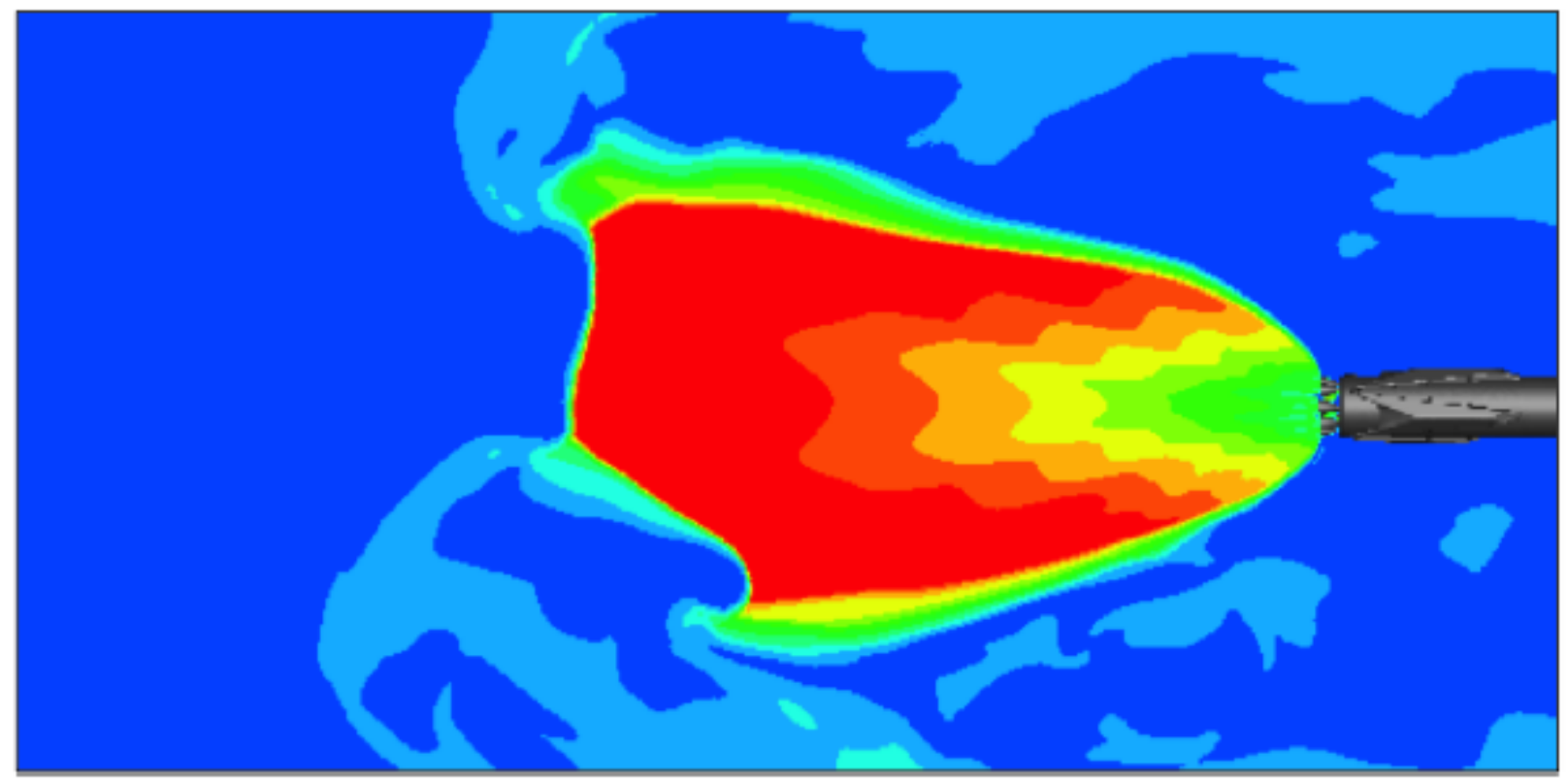

Figure 5 - Instantaneous Mach number contours as predicted by Fun3D for flight F9-10, Ref 20.

Mars EDL Design Analysis:

NASA's EDL systems analysis tools were employed to assess the feasibility of landing a largely unmodified Dragon2 capsule on Mars, as shown in Figure 6a. Following hypersonic entry, this approach employed supersonic retropropulsion to safely place a large-mass system on the Mars surface. Navigation, aerodynamic, aerothermodynamic, flight dynamic, propulsion, GN\&C and systems engineering aspects were considered, demonstrating that propulsive landing approach initiated in supersonic conditions is possible, albeit not mass optimal. As a result of its large ballistic coefficient, this system follows a significantly different atmospheric flight path than traditional robotic systems, transitioning to nearly horizontal hypersonic flight at low altitude.

These same trajectory characteristics and system performance were observed for even larger mass landed systems. As discussed in Ref. 2 (see Figure 6b), this SRP-based EDL architecture scaled well to human-class EDL systems. 


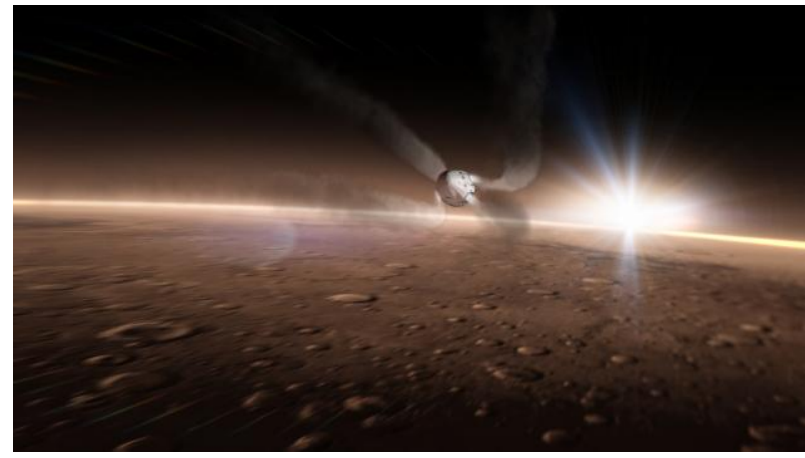

Figure 6a-Artist concept of Mars SRP configuration.

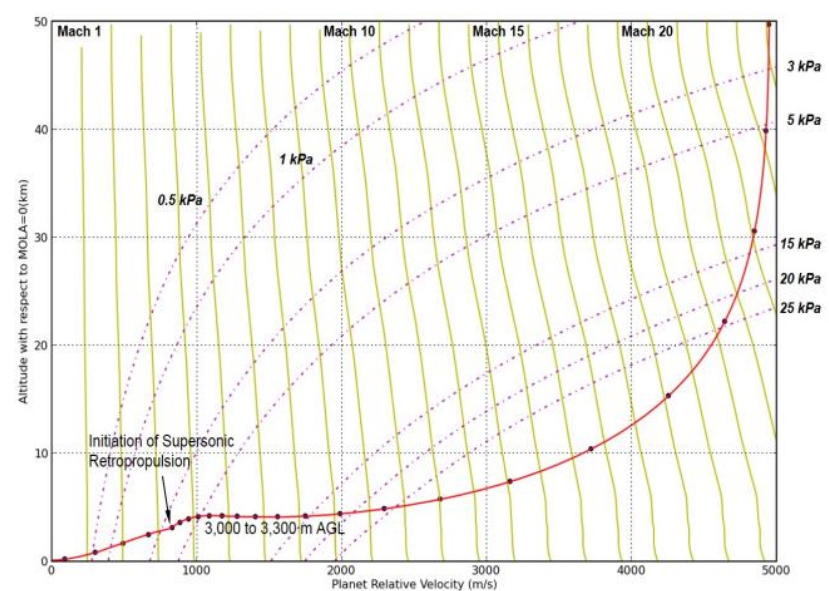

Figure $6 b-E D L$ trajectory for human-scale Mars SRP architecture, Ref. 2.

\section{Summary}

Advanced robotic and human missions to Mars require landed masses well in excess of current capabilities. One approach to safely land these large payloads on the Mars surface is to extend the propulsive capability currently required during subsonic descent to supersonic initiation velocities (supersonic retropropulsion). In September 2013, SpaceX performed the first supersonic retropropulsion (SRP) maneuver to decelerate the entry of the first stage of their Falcon 9 rocket. In FY 2014, NASA and SpaceX formed a three-year public-private partnership centered upon SRP data analysis. These activities focused on flight reconstruction, CFD analysis, a visual and infrared imagery campaign, and Mars EDL design analysis to advance the technology readiness of Mars SRP. Based on the analyses completed, the remaining SRP challenge is characterized as one of prudent flight systems engineering dependent on maturation of specific Mars flight systems, not technology advancement.

\section{Acknowledgements}

This work was funded by the National Aeronautics and Space Administration (NASA) Space Technology Mission Directorate through the Game Changing Development Program's Propulsive Descent Technologies project. Data was exchanged between NASA and the Space Exploration Technologies Corporation (SpaceX) through the NRSAA partnership Umbrella NRSAA-EA-14-18828. The authors are indebted to Paul Wooster for numerous discussions. Any opinions, findings, and conclusions or recommendations expressed in this material are those of the authors and do not necessarily reflect the views of SpaceX.

\section{References}

${ }^{1}$ Braun, R.D.; and Manning, R.M.: "Mars Entry, Descent and Landing Challenges.” Journal of Spacecraft and Rockets, Vol. 44, No. 2, pp. 310-323, Mar-Apr, 2007. 
${ }^{2}$ Price, H.W.; Braun, R.D.; Manning, R.M.; and Sklyanski, E.; “A High-Heritage Blunt-Body Entry, Descent, and Landing Concept for Human Mars Exploration,” AIAA 2016-0219, 2016 AIAA Science and Technology Forum and Exposition, San Diego, CA, January 2016.

3“"Entry, Descent and Landing Systems Analysis Study: Phase 1 Report," NASA TM 216720, July 2010.

4“'Entry, Descent and Landing Systems Analysis Study: Phase 2 Report on Exploration FeedForward Systems," NASA TM 217055, February 2011.

${ }^{5}$ Peterson, V. L., and McKenzie, R. L., "Effects of Simulated Retrorockets on the Aerodynamic Characteristics of a Body of Revolution at Mach Numbers from 0.25 to 1.90," NASA TN D1300, May 1962.

${ }^{6}$ Finley, P. J., "The Flow of a Jet from a Body Opposing a Supersonic Free Stream," Journal of Fluid Mechanics, Vol. 26, No. 2, 1966, pp. 337-368.

${ }^{7}$ Jarvinen, P. O., and Adams, R. H., "The Aerodynamic Characteristics of Large Angled Cones with Retrorockets," NASA CR NAS 7-576, Feb. 1970.

${ }^{8}$ Korzun, A.M.; Braun, R.D.; and Cruz, J.R.; “A Survey of Supersonic Retropropulsion Technology for Mars Entry, Descent and Landing," Journal of Spacecraft and Rockets, Vol. 46, No. 5, pp. 929-937, Sept-Oct, 2009.

${ }^{9}$ Korzun, A.M.; and Braun, R.D.; "Conceptual Modeling of Supersonic Retropropulsion Flow Interaction and Relationships to System Performance," Journal of Spacecraft and Rockets, Vol. 50, No. 6, pp. 1121-1133, Nov-Dec, 2013.

${ }^{10}$ Cordell, C.E.; and Braun, R.D.; "Analytical Modeling of Supersonic Retropropulsion Plume Structures,” Journal of Spacecraft and Rockets, Vol. 50, No. 4, pp. 763-770, July-Aug, 2013.

${ }^{11}$ Korzun, A.M.; Cordell, C.E.; and Braun, R.D.; "Computational Aerodynamic Predictions of Supersonic Retropropulsion Flowfields," Journal of Spacecraft and Rockets, Vol. 50, No. 5, pp. 950-960, Sept-Oct, 2013.

${ }^{12}$ Korzun, A.M.; and Braun, R.D.; “Application of a Reynolds-Averaged Navier-Stokes Approach to Supersonic Retropropulsion Flowfields," Journal of Spacecraft and Rockets, Vol. 50, No. 5, pp. 961-980, Sept-Oct, 2013.

${ }^{13}$ Kleb,W.; Schauerhamer, D.; Trumble, K.; Sozer, E.; Barnhardt, M.; Carlson, J-R.; and Edquist, K.T.; "Toward Supersonic Retropropulsion CFD Validation," 42nd AIAA Thermophysics Conference, Fluid Dynamics and Co-located Conferences, 2011, AIAA 2011-3490.

${ }^{14}$ Schauerhamer, D.; Trumble, K.; Kleb, W.; Carlson, J-R.; and Edquist, K.T.; "Continuing Validation of Computational Fluid Dynamics for Supersonic Retropropulsion," 50th AIAA Aerospace Sciences Meeting including the New Horizons Forum and Aerospace Exposition, Aerospace Sciences Meetings, 2012, AIAA 2012-0864. 
${ }^{15}$ Berry, S.A.; Rhode, M.N.; and Edquist, K.T.; "Supersonic Retropropulsion Experimental Results from the NASA Ames 9- x 7-Foot Supersonic Wind Tunnel;" AIAA 2012 -2074, 42nd AIAA Fluid Dynamics Conference, New Orleans, Louisiana, 2012.

${ }^{16}$ Berry, S.A.; Rhode, M.N.; Edquist, K.T.; and Player, C.J.; "Supersonic Retropropulsion Experimental Results from the NASA Langley Unitary Plan Wind Tunnel;"AIAA 2011-3489, 42nd AIAA Thermophysics Conference, Honolulu, Hawaii, 2011.

${ }^{17}$ Mandalia, A.B.; and Braun, R.D.; "Supersonic Retropropulsion Thrust Vectoring for Mars Precision Landing," Journal of Spacecraft and Rockets, Vol. 52, No. 3, pp. 827-835, May-June, 2015.

${ }^{18}$ Sforzo, B.; and Braun, R.D.; "Feasibility of Supersonic Retropropulsion Based on Assessment of Mars-Relevant Flight Data," AIAA Space Forum, September 2017, Orlando FL.

${ }^{19}$ Horvath, T.J.; Aubuchon, V.V.; Rufer, S.J.; Schwartz, R.J.; Mercer, C.D.; Tack, S.; Spisz, T.S.; Taylor, J.C.; Gibson, D.M.; Osei-Wusu, K.; Kennerly, S.; Scriven, G.; Pottebaum, T.; and Ross, M.; "Advancing Supersonic Retro-Propulsion Technology Readiness: Infrared Observations of the SpaceX Falcon 9 First Stage," AIAA Space Forum, September 2017, Orlando FL.

${ }^{20}$ Edquist, K.T.; Korzun, A.M.; Bibb, K.L.; Schauerhamer, D.G.; Ma, E.C.; McCloud, P.L.; Palmer, G.E.; and Monk, J.D.; "Comparison of Navier-Stokes Flow Solvers to Falcon 9 Supersonic Retropropulsion Flight Data," AIAA Space Forum, September 2017, Orlando FL. 